\title{
Prospective randomized study comparing the standard weight-based method and a novel method based on combined width of index, middle and ring fingers for ProSeal laryngeal mask airway size selection in paediatric patients
}

\author{
Shaji Mathew ${ }^{1}$, Yogesh Kanta Gaude ${ }^{2 *}$, Sahana Hiriyanna ${ }^{3}$, Arun Kumar Handigodu Duggappa, \\ Shiyad Muhamed ${ }^{2}$, Ajith Kumar Pillai ${ }^{2}$ \\ Professor ${ }^{l}$, Assistant Professor ${ }^{2}$, Junior Resident ${ }^{3}$, Associate Professor ${ }^{4}$, Kasturba Medical College, \\ Manipal, Karnataka, India.
}

\begin{abstract}
Introduction: Appropriate size selection of ProSeal laryngeal mask airway (PLMA) is an important prerequisite for successful use of the device. Size of PLMA is often selected based on weight of patients. We aimed to determine whether combined width of patient's index, middle and ring fingers could be used as an alternative to weight-based selection of appropriate size of PLMA.

Materials and methods: In this prospective randomized study, 102 patients aged 6 months to 10 years were included. Patients were allocated to one of two groups based on a randomization table and PLMA inserted according to the group allocated. In Group S, PLMA size selected according to weight-based method whereas in Group N, PLMA size was selected based on 3-finger breadth of patients. We recorded insertion parameters, fiberoptic scoring of glottic visualisation, airway manipulations and postoperative complications.

Results: In 68 children (66.66\%) size of PLMA was same according to both methods. The kappa coefficient was 0.461 concluding moderate agreement between two methods. In the remaining 34 children $(33.34 \%)$, the disagreement in sizes were with only one size, in whom the patient's weights were borderline values. The PLMA insertion time, ease of insertion, insertion attempts, fiberoptic view of position of device were comparable in both groups. There were no significant complications in the postoperative period.

Conclusion: Three finger breadth sizing method can be used as a good alternative to weightbased method for selecting appropriate size of PLMA in children.
\end{abstract}

Keywords: Paediatrics; laryngeal mask airway size; fiberoptic view of glottis.

\section{Introduction}

Supraglottic airway (SGA) devices are useful for elective as well as emergency airway cases in hospital and prehospital settings. ${ }^{1,2}$ The ProSeal LMA (PLMA), which is a second-generation SGA was introduced by Dr. Archie Brain in $2000 .^{3}$ To be used successfully in a patient, proper size selection of the device is important. Owing to the anatomical variations of upper airway as well as wider range of body weight as a selection criterion for a given size of PLMA, the weight-based size selection recommended by manufacture may not suit all patients. ${ }^{4,5}$

\footnotetext{
*Correspondence: Yogesh Kanta Gaude

E mail: yogeshgaude@gmail.com

https://orcid.org/0000-0001-9749-9597

Received: 01/03/2018

Accepted:12/05/2018

DOI: http://doi.org/10.4038/slja.v26i2.8320
}

Aim of the current study was to determine whether combined width of patient's index, middle and ring fingers can be used as an alternative to standard weight-based size selection of PLMA in children. This method is simple, convenient, easy to memorize and previous studies have shown its accuracy in determining the size of the PLMA. We aimed to compare the sizes of laryngeal mask airway determined with this method with the sizes determined according to body weight. This method will be an alternative to the standard weight-based size selection or when the clinician is unable to measure the weight as in bed ridden patients. Primary objective was to compare the sizes of PLMA based on patient's weight with that of 3 -fingers sizing method and to evaluate the agreement between two methods. Secondary objectives were to document insertion related parameters, fiberoptic scoring of position of the device and immediate postoperative complications.

\section{Subjects and Methods}

This double blinded randomized prospective study was commenced after obtaining approval of the 
departmental dissertation committee and hospital ethics committee. Paediatric patients aged 6 months to 10 years, weighing between 5 to $30 \mathrm{~kg}$ undergoing elective surgical procedures of short duration requiring general anaesthesia were included in the study. Patients with history of hyper-reactive airway disease, obesity, mental retardation, anticipated difficult airway and limb abnormality were excluded. There were 3 observers in the study. Observer 1 was a resident blinded to the group allocation, who evaluated the patients preoperatively, obtained written informed consent from the parents of the patients and recorded the study parameters. Observer 2 was an anaesthesiology consultant blinded to the group allocation, who introduced PLMA as provided by observer 3 and graded the fiberoptic view. Observer 3 was an unblinded additional consultant who selected PLMA based on group allocation. Patient's were allocated to one of the two groups based on a computer generated randomization table, duly maintaining allocation concealment using sequentially numbered opaque sealed envelopes. Sizes of PLMA were determined by the patient's weight and breadth of 3 fingers in all patients. In Group S (Standard) PLMA size was selected based on weight-based calculation. In Group N (Novel) size was selected based on finger breadth of the patients (three fingers sizing method). This consists of extending the right hand of patient with palm facing up and hand opened separating the thumb and little finger, keeping the index, middle and ring fingers extended but approximated. Laryngeal masks of different sizes were inflated with maximum volume of air as per the manufacturer's recommendation. Ventral surface of cuff of PLMA was applied against palmar side of index, middle and ring fingers held in approximation. The PLMA with its breadth matching best with the width of these three fingers was selected (Figure 1).

Figure 1: Novel method used to determine the size of PLMA

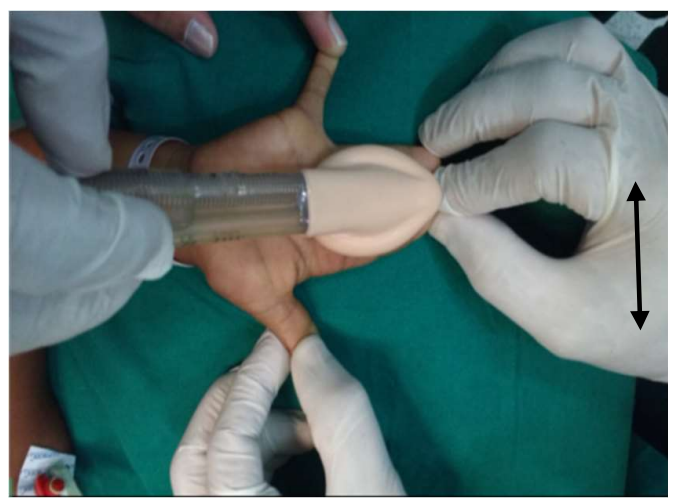

On the day of surgery patient's identity was confirmed, consent for anaesthesia as well as participation in study and nil per oral status was checked. All patients were premedicated with intravenous glycopyrrolate $10 \mu \mathrm{g} / \mathrm{kg}$ and midazolam $30 \mu \mathrm{g} / \mathrm{kg}$ after obtaining intravenous access in the operating room. Monitoring was commenced using 5lead ECG, pulse oximeter, waveform capnogram, noninvasive blood pressure and peripheral nerve stimulator. Sizes of PLMA would be noted by observer 3 by both the methods. Based on the group allocated, appropriate size of the device would be selected just before preoxygenation. Preoxygenation was done with $100 \% \mathrm{O}_{2}$ using Jackson-Rees circuit for children weighing $<15 \mathrm{~kg}$ and closed circuit with $\mathrm{CO}_{2}$ absorber for children weighing $>15 \mathrm{~kg}$. Induction was done with titrated doses of intravenous propofol and fentanyl $1-2 \mu \mathrm{g} / \mathrm{kg}$. Ability to ventilate the patient by bag and mask was confirmed and then neuromuscular blockade was achieved using intravenous atracurium $0.5-0.6 \mathrm{mg} / \mathrm{kg}$. Anaesthetic depth deepened with sevoflurane (3\%) in 100\% oxygen using bag mask ventilation. Once TOF count was zero, PLMA of adequate size as per group allocation was inserted using inventor's method and cuff was inflated to a pressure less than $60 \mathrm{cmH}_{2} \mathrm{O}$.

Appropriate placement of PLMA and ventilation was determined by chest movement, auscultation of breath sounds, capnography and lack of gastric insufflation. Presence of gastric insufflation was determined by auscultation over epigastrium. Automated ventilation was provided with tidal volume $7-10 \mathrm{ml} / \mathrm{kg}$ and respiratory rate adjusted so as to obtain an end-tidal carbon dioxide $\left(\mathrm{ETCO}_{2}\right)$ between $35-40 \mathrm{mmHg}$. Insertion related parameters assessed were insertion time, number of attempts at placement and ease of insertion. Time for successful insertion was recorded in seconds from the introduction of PLMA between the teeth to sustained appearance of waveform capnogram. Ease of PLMA placement was assessed subjectively on a scale from 1 to 4 (1 - No resistance, 2 - Mild resistance, 3 Moderate resistance, 4 - Inability to place the device appropriately). Placement of the device was assessed by fiberscopy (OD - $2.4 \mathrm{~mm}$, Pentax corporation, Japan) through airway tube and the view was scored using Brimacombe score (1 - Vocal cords not seen, 2 - Vocal cords and anterior epiglottis seen, 3 - Vocal cords and posterior epiglottis seen, 4 - Only vocal cords visible). ${ }^{6}$ In our study score of $\geq 3$ were considered as good view. After confirming placement of PLMA, well lubricated gastric tube $(6 \mathrm{Fr}, 8 \mathrm{Fr}$ and 10 Fr sizes for $1.5,2$ and 2.5 sized airway devices respectively) was passed through the dedicated 
channel meant for gastric tube insertion. Correct placement of tip of gastric tube was assessed by aspiration of gastric fluid or detection of injected air by auscultation over epigastrium. Ease of gastric tube insertion was graded subjectively (1 - Very easy, 2 Easy, 3 - Difficult, 4 - Very difficult). Number of airway manipulations such as gentle advancement/withdrawal of device without removal, jaw thrust, or neck extension required to maintain airway patency were documented. Failed attempt was defined as unsuccessful device placement within 3 attempts, lack of square wave capnogram or inadequate ventilation (desaturation $<92 \%$ or abnormal thoraco-abdominal movements). In cases of failed attempt, endotracheal intubation was performed using direct laryngoscopy. After the completion of surgery, NMB was antagonised using intravenous neostigmine $0.05 \mathrm{mg} / \mathrm{kg}$ and glycopyrrolate $0.01 \mathrm{mg} / \mathrm{kg}$. PLMA was removed once the child regained full consciousness and was easily arousable. Postoperative complications like presence of blood stains on PLMA, soft tissue trauma and stridor were also recorded.

Weight based size selection of PLMA recommended by manufacturer is as follows: for weight up to $5 \mathrm{~kg}$ PLMA size 1 and 1.5; up to $10 \mathrm{~kg}$ - size of 2 and 2.5; up to $20 \mathrm{~kg}$ - size of 2 and 2.5 ; up to $30 \mathrm{~kg}$ - size of 2.5 and 3. To standardize this, we have chosen PLMA as follows; for weight of $5 \mathrm{~kg}$ PLMA size 1 , weight of $10 \mathrm{~kg}$ - size 1.5 , weight of $20 \mathrm{~kg}$ - size 2 , and for weight of $30 \mathrm{~kg}$-size 2.5 .

Sample size was calculated based on study conducted by L Gallart et al. ${ }^{7}$ An assumption was made that success rate of standard weight-based method of $90 \%$ and 3 -finger breadth method of $65 \%$ based on the study. Sample size was based on comparison of proportions. For the study to have $80 \%$ power and to detect a difference of $25 \%$ with $5 \%$ type I error and $20 \%$ type II error, the sample size required was 51 in each group. Data analysis was done using statistical package for the social science system for Windows version 20 (SPSS Inc., Chicago, USA). Chi-square test, kappa coefficient and Independent t-test were used in the study.

\section{Results}

A total of 102 patients were included in the study, all of whom completed the study. The age, weight and duration of surgery were comparable between groups (Table 1). The distribution of 102 patients with sizes of the PLMA determined by both methods is presented in Table 2 . In 68 patients $(66.66 \%)$, the size of the PLMA coincided with both the methods, with calculated kappa coefficient being 0.461 . There was moderate level of agreement between the methods. In 68 patients who had agreement between both methods, 30 patients belonged to Group $\mathrm{N}$ and 38 patients belonged to Group S (Table 2). Insertion time, number of insertion attempts, and ease of insertion were comparable between the groups (Table 4A and 4B). Glottic view obtained with fiberscopy and ease of gastric tube placement were comparable between the groups (Table 5 and 6). None of the patients had any post-operative complications.

Table 1: Patient characteristics

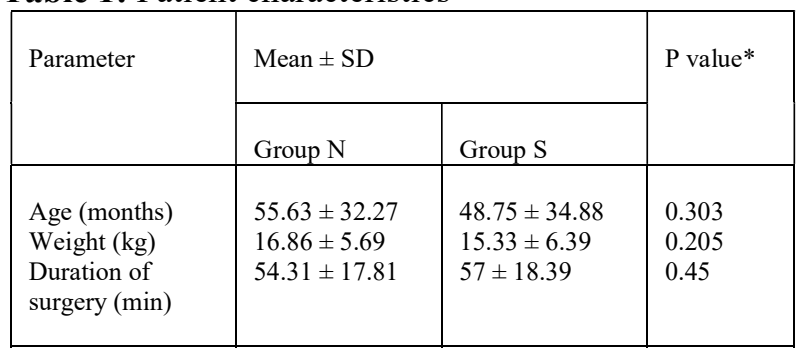

*Independent t-test

Table 2: Distribution of the patients according to the PLMA sizes derived from body weight and three finger breadth methods

\begin{tabular}{|l|l|l|l|l|l|}
\hline \multicolumn{2}{|c|}{} & \multicolumn{2}{|l|}{$\begin{array}{l}\text { PLMA size by 3-finger breadth } \\
\text { method }\end{array}$} & \multirow{2}{*}{ Total } \\
\cline { 2 - 6 } \multicolumn{2}{|c|}{} & 1.5 & 2 & 2.5 & \\
\hline $\begin{array}{l}\text { PLMA } \\
\text { size by } \\
\text { weight- } \\
\text { based } \\
\text { method }\end{array}$ & 1.5 & $\begin{array}{l}\mathbf{1 3} \\
\mathbf{( 4 + 9 )}\end{array}$ & $\begin{array}{l}12 \\
(7+5)\end{array}$ & 0 & 25 \\
\cline { 2 - 6 } & 2 & $\begin{array}{l}1 \\
(0+1)\end{array}$ & $\begin{array}{l}\mathbf{3 7} \\
\mathbf{( 1 6 + 2 1 )}\end{array}$ & $\begin{array}{l}20 \\
(13+7)\end{array}$ & 58 \\
\cline { 2 - 6 } & 2.5 & 0 & $\begin{array}{l}1 \\
(1+0)\end{array}$ & $\begin{array}{l}\mathbf{1 8} \\
\mathbf{( 1 0 + 8 )}\end{array}$ & 19 \\
\hline \multirow{2}{*}{ Total } & 14 & 50 & 38 & 102 \\
\hline
\end{tabular}

Values in bracket indicate number of patients in whom 3-finger breadth method and weight-based methods were used for PLMA size selection respectively. Bold data ((diagonal line) indicates the number of patients in whom both methods were in agreement. 
Table 3: Weight of the patients for each combination of size of PLMA

\begin{tabular}{|l|l|l|l|l|}
\hline \multicolumn{2}{|l|}{} & \multicolumn{2}{|l|}{ PLMA size by 3-finger breadth method } \\
\cline { 2 - 5 } & \multicolumn{4}{|l|}{} \\
\cline { 2 - 5 } & 1.5 & 2 & 2.5 \\
\hline $\begin{array}{l}\text { PLMA size } \\
\text { by weight } \\
\text { based } \\
\text { method } \\
\text { (kg) }\end{array}$ & 1.5 & $\mathbf{8 . 1 5} \pm \mathbf{1 . 2 8}$ & $8.73 \pm 0.71$ & - \\
\cline { 2 - 5 } & 2 & 14.00 & $\mathbf{1 4 . 4 3} \pm \mathbf{2 . 5 4}$ & $16.86 \pm 2.32$ \\
\cline { 2 - 5 } & 2.5 & - & 16.00 & $\mathbf{2 3 . 9 4} \pm \mathbf{3 . 1 7}$ \\
\hline
\end{tabular}

Data are expressed as Mean \pm SD wherever applicable

Bold data (diagonal line) show the mask size that coincides for both methods

Table 4A: PLMA insertion parameters

\begin{tabular}{|l|l|l|l|}
\hline & $\begin{array}{l}\text { Group N } \\
(\mathrm{n}=51)\end{array}$ & $\begin{array}{l}\text { Group S } \\
(\mathrm{n}=51)\end{array}$ & P value \\
\hline $\begin{array}{l}\text { Insertion time } \\
\text { (seconds) } \\
\text { Mean } \pm \text { SD }\end{array}$ & $17.9 \pm 4.55$ & $16.96 \pm 2.95$ & $0.218^{*}$ \\
\hline $\begin{array}{c}\text { Insertion } \\
\text { attempts } \\
1 / 2\end{array}$ & $51 / 0$ & $50 / 1$ & $0.310^{\dagger}$ \\
\hline
\end{tabular}

* Independent t-test $\uparrow$ Chi-square test

Table 4B: PLMA insertion parameters

\begin{tabular}{|l|l|l|l|}
\hline $\begin{array}{l}\text { Ease of } \\
\text { PLMA } \\
\text { insertion } \\
\text { scale }\end{array}$ & $\begin{array}{l}\text { Group N } \\
(\mathrm{n}=51)\end{array}$ & $\begin{array}{l}\text { Group S } \\
(\mathrm{n}=51)\end{array}$ & \multirow{2}{*}{ P value* 1.00 } \\
\hline 1 & 50 & 50 & \\
\hline 2 & 1 & 1 & \\
\hline 3 & 0 & 0 & \\
\hline 4 & 0 & 0 & \\
\hline
\end{tabular}

* Chi-square test
Table 5: Fibreoptic scoring of position of PLMA

\begin{tabular}{|l|l|l|l|l|}
\hline $\begin{array}{l}\text { Brimacombe } \\
\text { score }\end{array}$ & $\begin{array}{l}\text { Group N } \\
(\mathrm{n}=51)\end{array}$ & $\begin{array}{l}\text { Group S } \\
(\mathrm{n}=51)\end{array}$ & $\begin{array}{l}\text { Total } \\
(\mathrm{n}=102)\end{array}$ & $\begin{array}{l}\text { P value } \\
0.501^{*}\end{array}$ \\
\hline 1 & 0 & 1 & 1 & \\
\cline { 1 - 4 } & 1 & 2 & 3 & \\
\cline { 1 - 3 } & 16 & 20 & 36 & \\
\hline 4 & 34 & 28 & 62 & \\
\hline
\end{tabular}

Table 6: Gastric tube placement

\begin{tabular}{|l|l|l|l|}
\hline $\begin{array}{l}\text { Ease of gastric } \\
\text { tube insertion }\end{array}$ & $\begin{array}{l}\text { Group N } \\
(\mathrm{n}=51)\end{array}$ & $\begin{array}{l}\text { Group S } \\
(\mathrm{n}=51)\end{array}$ & $\begin{array}{l}\text { Total } \\
(\mathrm{n}=102)\end{array}$ \\
\hline 1 & 12 & 6 & 18 \\
\hline 2 & 37 & 41 & 78 \\
\hline 3 & 2 & 4 & 6 \\
\hline 4 & 0 & 0 & 0 \\
\hline
\end{tabular}

\section{Discussion}

The Laryngeal mask airway has emerged as a formidable choice over endotracheal tube (ETT) in scenarios where endotracheal intubation is not mandatory. ${ }^{8}$ Most of the clinicians use weight related method for the selection of PLMA. Owing to the anatomical variations of upper airway as well as wider range of body weight as a selection criterion for a given size of PLMA, manufacturer's recommendation of size based on body weight may not be applicable to all patients. Moreover, when the patient's weight is not known or the clinician is not able to recall the relationship between weight and size, an alternative simple method can be useful. Several authors have described alternative methods for choosing an appropriate size of LMA. ${ }^{9,10,11}$ The alternative method should be simple, accurate and easy to perform at bed side. There are other alternative methods proposed in literature according to gender, height, external ear and width of tongue. ${ }^{12-}$

Our objective was to search for a simple and accurate alternative method to select the proper size of PLMA. Similar study was done by Gallart et al using cLMA. ${ }^{7}$ 
In this study we compared the standard weight-based method with a novel method based on combined width of index, middle and ring fingers for size selection of PLMA, which will be an addition to the existing methods. We allocated 102 paediatric patients randomly to one of two groups and PLMA was inserted according to the group. Our study revealed a moderate level of agreement regarding distribution of patients according to the sizes of mask derived from weight and three finger breadth method (Table 2). In 68 (66.66\%) patients, size of PLMA was same by both the methods. Among the remaining 34 (33.34\%) patients, 2 patients had one size lower PLMA compared to standard method and in 32 patients, one size higher PLMA was found to be appropriate by 3-finger breadth method when compared to standard method. There was disagreement by only one size in 34 patients between two methods. In none of the patients, two sizes difference was observed. In patients in whom a disagreement between the two methods were observed, patient's weights were borderline values which indicates the choice of different size of PLMA which may be lower or higher (Table 3). In such situations anatomical features like measurement of the width of fingers may help in deciding the size of PLMA. Data were analyzed statistically to find the level of agreement between two methods. In our study level of agreement was moderate with kappa coefficient being 0.461 . Gallart et al in their study using cLMA found an excellent agreement between the two methods with a kappa coefficient of $0.81{ }^{7}$

Method of insertion of LMA, insertion parameters and glottic view was not documented by Gallart et al in their study. In our study insertion parameters and anatomical position of the device using fiberscopy were recorded. ${ }^{6}$ Insertion time, insertion attempts and ease of PLMA placement were comparable between the groups (Table 4A and 4B).

Placement of device as assessed by fiberscopy and graded using Brimacombe score, which were statistically comparable in both the groups (Table 5). Sixty-two patients had grade 4 view (34 patients belonged to Group $\mathrm{N}$ and 28 patients belonged to Group S), whereas 36 patients had grade 3 view (16 belonged to Group N and 20 belonged to Group S). Ease of insertion of gastric tube was comparable between groups (Table 6).

None of the patients in both the groups required any intraoperative manoeuvre and none of them had any postoperative complications. Out of 32 patients who had required higher size PLMA according to 3-finger breadth method, 20 patients belonged to Group $\mathrm{N}$ $(7+13)$ and PLMA was placed according to 3 -finger breadth method without encountering any complications (Table 2).

Our study has certain merits. This method to determine the appropriate size of PLMA is easy and feasible at bed side. Being an interventional study, different insertion parameters including fiberoptic scoring of position of device were studied using predefined criteria. In our study $66.67 \%$ had agreement between two methods and remaining $33.33 \%$ patients had disagreement by one size of PLMA. One size disagreement could be attributed to nutritional disorders or to borderline weight, which remains inconclusive. However, insertion of PLMA was atraumatic and ventilation was adequate in both the groups. So, in patients whose weight is at borderline or in those with nutritional disorders wherein PLMA size as derived by weight-based method might be confusing or overlapping, the 3finger breadth method can help to decide the appropriate size of the PLMA.

There are few limitations in our study. Owing to the ethical considerations of placing two different PLMA's as derived by two methods in the same patient, we could not assess insertion parameters of two sizes of PLMA as derived by both methods in the same patient. The study was conducted in a limited group of patients, hence further studies are required in children less than 6 months of age and with nutritional disorders.

To conclude, weight-based method and 3-finger breadth method for the selection of ProSeal laryngeal mask airway in paediatric patients are in moderate level of agreement. Ease of insertion, number of attempts, fiberoptic view of glottis and ease of gastric tube insertion are comparable in both groups. The 3finger breadth sizing can be used as a good alternative to standard weight-based method for the selection of ProSeal laryngeal mask airway in paediatric patients.

\section{References}

1. Brain AI, Verghese C, Strube PJ. The LMA 'ProSeal' a laryngeal mask with an oesophageal vent. $\mathrm{Br} \mathrm{J}$ Anaesth 2000;84:650-4. https://doi.org/10.1093/bja/84.5.650 PMid: 10844848

2. Hernandez MR, Klock PA Jr, Ovassapian A. Evolution of the extraglottic airway: a review of its history, applications and practical tips for success. AnesthAnalg 2012;114:349-68. 
Gaude et al. Sri Lankan Journal of Anaesthesiology: 26(2):118-123(2018)

https://doi.org/10.1213/ANE.0b013e31823b6748 PMid:22178627

3. Dorsch JA, Dorsch SE. Supraglottic airway devices. In: Dorsch JA, Dorsch SE, editors. Understanding anaesthesia equipment. 5th ed. Lippincott Williams and Wilkins; 2008. p. 462-6.

4. Solanki SL, Doctor JR, Shekhawat KK, et al. Comparison of actual and ideal body weight for selection of appropriate size of ProSeal ${ }^{\mathrm{TM}}$ laryngeal mask airway in overweight and obese patients: A prospective, randomised study. Indian $\mathrm{J}$ Anaesth 2017;61:398-403.

https://doi.org/10.4103/ija.IJA 6917

PMid:28584349 PMCid:PMC5444218

5. Kim HJ, Park MJ, Kim JT, et al. Appropriate laryngeal mask airway size for overweight and underweight children. Anaesthesia 2010;65:50-3. https://doi.org/10.1111/j.1365-2044.2009.06160.x PMid:19922510

6. Brimacombe J, Berry A. A proposed fibreoptic scoring system to standardize the assessment of laryngeal mask airway position. AnaesthAnalg 1993;76:4.

7. Gallart L, Mases A, Martinez J. simple method to determine the size of the laryngeal mask airway in children. Eur J Anaesthesiol 2003;20:570-4. https://doi.org/10.1097/00003643-200307000-00010 PMid:12884992

8. Voyagis GS, Photakis D, Kellari A, et al. The laryngeal mask airway: a survey of its usage in 1,096 patients. Minerva Anestesiol 1996;62:277-80. PMid:9038036

9. Kagawa T, Obara H: An easy formula to remember the laryngeal mask airway size-patient weight relationship. Anesthesiology 2000;92:631-2. https://doi.org/10.1097/00000542-200002000-00063

10. Hirai S, Nakamura R, Mackana N. Alternative formula for laryngeal mask airway size selection. Anesthesiology 2004;100:460. https://doi.org/10.1097/00000542-200402000-00054 PMid:14739834
11. Ho AM, Karmakar MK, Dion PW. Choosing correct laryngeal mask airway sizes and cuff inflation volumes in paediatric patients. J Emerg Med 2008;35:299-300.

https://doi.org/10.1016/j.jemermed.2007.10.073

PMid:18462912

12. Voyagis GS, Batzioulis PG, Secha-Doussaitou PN. Selection of the proper size of laryngeal mask airway in adults. AnesthAnalg 1996;83:663-4.

https://doi.org/10.1213/00000539-199609000-00062 PMid:8780315

13. Berry AM, Brimacombe J, McManus KF, Goldblatt M. An evaluation of the factors influencing selection of the optimal size of laryngeal mask airway in normal adults. Anaesthesia 1998;53:565-70.

https://doi.org/10.1046/j.1365-2044.1998.00403.x PMid:9709143

14. Zahoor A, Ahmad N, Sereche G, Riad W. A novel method for laryngeal mask airway size selection in paediatric patients. Eur J Anaesthesiol 2012; 29:38690.

https://doi.org/10.1097/EJA.0b013e32835562f4 PMid:22692042

15. Haliloglu M, Bilgen S, Uzture N, Koner O. Simple method for determining the size of the ProSeal laryngeal mask airway in children: a prospective observational study. Rev Bras Anestesiol 2017;67:1520.

https://doi.org/10.1016/j.bjan.2016.09.007

PMid:27692804

16. Huang $\mathrm{H}$, Cherng $\mathrm{CH}$. Optimal size selection of the classic laryngeal mask airway by tongue width based method in adult males. Journal of the Chinese medical association 2014;77:422-5. https://doi.org/10.1016/i.jcma.2014.05.009

PMid:25043385 